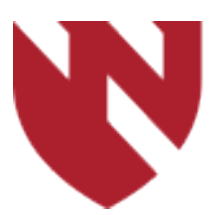

December 2019

\title{
Comparison of Post-Operative Outcomes of Ciprofloxacin Otic Suspension versus Ciprofloxacin-Dexamethasone Otic Drops in Myringotomy with Tube Placement
}

\author{
Andrew W. Logeman \\ University of Nebraska Medical Center \\ Daniel V. Arkfeld \\ University of Nebraska Medical Center \\ Jayme R. Dowdall \\ University of Nebraska Medical Center \\ Dwight T. Jones \\ University of Nebraska Medical Center
}

Tell us how you used this information in this short survey.

Follow this and additional works at: https://digitalcommons.unmc.edu/gmerj

Part of the Higher Education Commons, and the Medicine and Health Sciences Commons

\section{Recommended Citation}

Logeman, A. W., Arkfeld, D. V., Dowdall, J. R., , Jones, D. T. Comparison of Post-Operative Outcomes of Ciprofloxacin Otic Suspension versus Ciprofloxacin-Dexamethasone Otic Drops in Myringotomy with Tube Placement. Graduate Medical Education Research Journal. 2019 Dec 13; 1(1).

https://digitalcommons.unmc.edu/gmerj/vol1/iss1/81

This Conference Proceeding is brought to you for free and open access by DigitalCommons@UNMC. It has been accepted for inclusion in Graduate Medical Education Research Journal by an authorized editor of DigitalCommons@UNMC. For more information, please contact digitalcommons@unmc.edu. 


\section{Comparison of Post-Operative Outcomes of Ciprofloxacin Otic Suspension versus Ciprofloxacin-Dexamethasone Otic Drops in Myringotomy with Tube Placement}

Creative Commons License

(c) $(1) \Theta$

This work is licensed under a Creative Commons Attribution-Noncommercial-No Derivative Works 4.0 License. 


\section{Patterns of Opiate Use and Prescription Practices in Isolated Orthopaedic Trauma Injuries: Creating Guidelines}

Matthew Mormino, Justin Siebler, Sara Putnam, David Kusin, Zachary Bailey, Todd Gilbert, Emmett Gannon, Josh Locker, Matthew Tingle,

Matthew Freeman, Mark Amirtharaj

Mentor: Matthew Mormino

Program: Orthopaedic Surgery

Purpose: The purpose of this study is to quantify our opiate prescription practices and to reduce our prescriptions while still providing adequate pain relief.

Background: There has been an alarming increase in the rate of opiate prescriptions in the United States in recent years, with $80 \%$ of the global supply of opiates being consumed in the United States. Orthopaedic surgeons are partly responsible for this, but there is a wide variation of prescription practices within the specialty with no established guidelines. Excessive opiate prescription is associated with the development of addiction, increased risk of hip fracture, nonunion, and lethal overdose. Furthermore, there is growing evidence that increased opiate use does not correlate with pain control as strongly as psychosocial variables, and that pharmacologic alternatives may be equally effective in reducing postoperative pain.

Methods: This will be a prospective study with two parts, each lasting about 6 months. The first part will quantify the baseline narcotic prescription habits of three orthopaedic trauma surgeons in the operative or nonoperative treatment of adult patients with isolated extremity trauma. Patients with a history of mental illness and chronic narcotic use or substance abuse will be excluded. Visual Analog Pain scores and opiate use in morphine equivalents will be collected on standardized forms at each postoperative visit. These data will be used to formulate new prescription guidelines that will then be implemented for six months and assessed with the same forms.

Results: Pending

https://doi.org/10.32873/unmc.dc.gmerj.1.1.080

\section{Comparison of Post-Operative Outcomes of Ciprofloxacin Otic Suspension versus Ciprofloxacin- Dexamethasone Otic Drops in Myringotomy with Tube Placement Andrew W Logeman, Daniel V Arkfeld, Jayme R Dowdall, Dwight T Jones}

\section{Mentor: Dwight T Jones \\ Program: Otolaryngology Head and Neck Surgery}

Background and Objectives: Myringotomy with tubes is the most common procedure performed by Otolaryngologists. There is no standard of care regarding post-operative medication use. The objective of this study was to compare post-operative complications including otorrhea, extrusion, and obstruction between the two medications.

Methods: A retrospective chart review was performed on children who underwent myringotomy with tube placement from

\section{Gender Difference in Glenoid Remodeling \\ Kent Rinehart, Matt Teusink, Chris Peters, AnnZajicek}

Mentor: Matt Teusink

Program: Orthopaedic Surgery

Introduction: The purpose of this study is to compare glenoid morphology and wear patterns between male and female patients with primary shoulder osteoarthritis.

Methods: A retrospective review of all patients who underwent an anatomic total shoulder arthroplasty by a single surgeon (MJT) for the diagnosis of primary osteoarthritis between August 2013 and July 2017. All patients had preoperative CT scans as part of their routine surgical planning. A total of 128 shoulders met our inclusion criteria. Glenoid version, inclination, and vault depth were measured by a fellowshiptrained musculoskeletal radiologist. Glenoid wear pattern was also classified according to
February 2016 to February 2017 under a single surgeon at a single institution. Each ear received either ciprofloxacin-dexamethasone otic drops (CDOD) or ciprofloxacin otic suspension (COS). Statistical analysis was used to compare the complication rates between the two groups depending on middle ear status at the time of surgery.

Results: 210 total patients identified, with 245 ears receiving CDOD and 99 receiving COS. For dry and mucoid middle ears at the time of surgery, there was no statistical difference between the use of CDOD and COS when assessing for post-operative complications.
For serous middle ears, $2 \%$ of CDOD ears and $12 \%$ of COS ears were obstructed with $\mathrm{p}=0.0176$. Additionally, $2 \%$ of CDOD ears and $22 \%$ COS ears had otorrhea with $\mathrm{p}=0.0001$. There was no difference in tube extrusion in serous ears.

Conclusion: No differences in post-operative complications were appreciated for mucoid or dry ears. Serous ears showed a significant increase in post-operative otorrhea and obstruction in COS compared to CDOD. CDOD should be used in serous ears. https://doi.org/10.32873/unmc.dc.gmerj.1.1.081 central wear amongst females, which was statistically significant ( $\mathrm{P}$-value $<0.0001$ ).

Discussion: This data reveals differences in glenoid wear between osteoarthritic males and female shoulders. Males demonstrate preferential posterior glenoid remodeling whereas females remodel centrally. The posterior wear pattern in males likely contributes to the relative increased posterior glenoid version as compared to females. The central wear pattern in females likely contributes to the relative smaller glenoid vault depth. https://doi.org/10.32873/unmc.dc.gmerj.1.1.082 